Proceedings of the ASME 2020

Pressure Vessels \& Piping Conference

PVP2020

July 19-24, 2020, Minneapolis, Minnesota, USA

PVP2020-21267

\title{
CRITICAL REVIEW OF ASME III PLASTICITY CORRECTION FACTORS FOR FATIGUE DESIGN-BY-ANALYSIS OF NUCLEAR POWER PLANT COMPONENTS
}

\author{
David M. Clarkson ${ }^{1}$, Christopher D. Bell \\ Rolls-Royce plc \\ Derby, UK
}

\author{
Donald Mackenzie \\ Department of Mechanical \& \\ Aerospace Engineering \\ University of Strathclyde \\ Glasgow, UK
}

\begin{abstract}
Despite significant technological progress in recent years, elastic-plastic fatigue analysis of pressure-retaining components remains a time-consuming venture. Accordingly, nuclear pressure vessel design codes such as ASME Section III provide simplified elastic-plastic analysis procedures as a practical alternative. This approach can be excessively conservative under certain conditions due to the bounding nature of the applied plasticity correction factor, $K_{e}$. Whilst this overconservatism was tolerable in the past, recent technical challenges arising due to consideration of environmentally-assisted fatigue (EAF) and design for long-term operation have posed difficulty in achieving acceptable fatigue usage based on extant Code assessment procedures for certain components. The incorporation of more accurate $K_{e}$ factors has since been identified as a nuclear industry priority.

This paper presents a critical review of $K_{e}$ factors within ASME Section III, with particular attention given to a recently proposed approach by Ranganath, which is currently being considered for inclusion as an ASME Section III Code Case. Correction factors adopted within other nuclear and nonnuclear codes and standards (C\&S) were also considered. The code-based $K_{e}$ factors were compared with $K_{e}$ factors obtained directly from various elastic-plastic finite element $(F E)$ models of representative plant components. The results revealed a considerable difference in conservatism between the code-based methods. Based on the elastic-plastic FE results, an alternative improved plasticity correction method was proposed. The need for a harmonized approach to determining $K_{e}$ based on elasticplastic FE analysis is discussed and identified as a desirable industry objective.

\section{ABSTRACT}




$\begin{array}{ll}\mathrm{S}_{\mathrm{y}} & 0.2 \% \text { proof stress } \\ \text { SDO } & \text { Standards Development Organisation } \\ \text { WRC } & \text { Welding Research Council } \\ & \\ \Delta \varepsilon_{\text {eff }}{ }^{\text {Dowling }} & \text { Dowling's effective strain range } \\ \Delta \varepsilon_{\text {eff }}{ }^{\mathrm{MP}} & \text { Maximum principal total strain range } \\ \Delta \varepsilon_{\mathrm{VM}}{ }^{\mathrm{e}} & \text { von Mises elastic strain range } \\ \Delta \varepsilon_{\mathrm{VM}}{ }^{\mathrm{p}} & \text { von Mises plastic strain range } \\ v & \text { Elastic Poisson's Ratio }\end{array}$

\section{INTRODUCTION}

Pressure-retaining components of civil pressurized water reactor (PWR) plants are susceptible to low-cycle fatigue. In the UK civil nuclear industry, the assurance of such components against fatigue failure is achieved by satisfying the elastic design-by-analysis (DBA) requirements outlined in Section III of the ASME Boiler and Pressure Vessel Code (BPVC) [1]. ASME III, Appendix XIII-3520 provides a systematic procedure to evaluate fatigue at a single location in a vessel based on stress ranges obtained from elastic analysis. To account for potential enhancement of strain due to plasticity, a plasticity correction factor, denoted by the symbol $\mathrm{K}_{\mathrm{e}}$ in Appendix XIII-3450, is applied to the elastic stress range for input into the fatigue design curve.

Since its inception in the 1971 edition of the Code, the Appendix XIII-3450 $\mathrm{K}_{\mathrm{e}}$ has remained unchanged, despite being widely acknowledged to be excessively conservative for cyclic thermal loading typically experienced by PWR components. Accordingly, in recent years, considerable industry effort has focused on the development of alternative plasticity correction factors, which more accurately capture the actual elastic-plastic structural response at critical locations. A number of these alternative proposals have subsequently been incorporated into other internationally recognised design codes and standards (C\&S). Today, there now exist considerable differences in the methodology and technical basis underpinning the various codebased $\mathrm{K}_{\mathrm{e}}$ factors.

This paper investigates the performance of code-based $\mathrm{K}_{\mathrm{e}}$ factors by direct comparison with the plasticity correction factors derived from elastic-plastic FE models for typical cyclic thermal loading conditions. For the sake of brevity, the results presented herein are limited to austenitic stainless steel, which tends to be the most susceptible to fatigue damage in the PWR operating environment.

\section{ASME III APPENDIX XIII-3450}

The technical basis of the ASME III, Appendix XIII-3450 $\mathrm{K}_{\mathrm{e}}$ dates back to the work of Langer [2], who defined $\mathrm{K}_{\mathrm{e}}$ as the ratio of the elastic-plastic peak strain to the strain calculated using Hooke's law. Langer derived analytical $\mathrm{K}_{\mathrm{e}}$ solutions for two simple configurations, namely a tapered flat bar loaded in tension, and a cantilever beam subjected to a end-point vertical displacement, under the assumption of power law hardening behavior. The current form of the XIII-3450 $\mathrm{K}_{\mathrm{e}}$ factor is given by Eq. (1), where the maximum $\mathrm{K}_{\mathrm{e}}$ value of $1 / n$ is derived from the tapered flat bar solution with a $2 / 3$ reduction in cross-section, which was determined to be realistically bounding. Variables $m$ and $n$ are material-dependent constants, where $n$ represents the monotonic strain hardening exponent of the material. For austenitic stainless steels, $m$ and $n$ are 1.7 and 0.3 respectively, and thus the maximum attainable $\mathrm{K}_{\mathrm{e}}$ factor of 3.33 is conceded for $\mathrm{S}_{\mathrm{n}} / \mathrm{S}_{\mathrm{m}}$ exceeding 5.1.

$$
K_{e}= \begin{cases}1.0 & \text { if } S_{n} \leq 3 S_{m} \\ 1.0+\frac{1-n}{n(m-1)}\left(\frac{S_{n}}{3 S_{m}}-1\right) & \text { if } 3 S_{m}<S_{n}<3 m S_{m} \\ \frac{1}{n} & \text { if } S_{n} \geq 3 m S_{m}\end{cases}
$$

In the ASME Code, a distinction is drawn between surface and sectional plasticity effects, where the latter is presumed to occur when the limit of $3 \mathrm{~S}_{\mathrm{m}}$ on the primary-plus-secondary (linearized) stress intensity range $\left(\mathrm{S}_{\mathrm{n}}\right)$ is exceeded. ASME III, Appendix XIII-2500 also provides a procedure to correct for the effects of surface plasticity arising due to the increase in the Poisson's ratio under constant volume plastic deformation. Appendix XIII-2500 is applied in lieu of Appendix XIII-3450 in the event that the total stress intensity $\left(\mathrm{S}_{\mathrm{p}}\right)$ exceeds twice the $0.2 \%$ proof stress $\left(S_{y}\right)$, and $S_{n}$ does not exceed $3 S_{m}$, but otherwise need not be applied. Appendix XIII-2500 is not considered in this paper, as it varies as a function of the expected number of repetitions of the applicable fatigue pair, and thus is not readily comparable with the other methods.

\section{ASME CODE CASE N-779 (ADAMS' METHOD)}

ASME Code Case (CC) N-779 is currently the only alternative to Appendix XIII-3450, and is based on the proposal by Adams [3]. CC N-779 differs from Appendix XIII-3450 as it explicitly distinguishes between stresses arising due to mechanical and thermal loads. To apply CC N-779 requires determination of three additional categories of stress, the thermal bending stress range $\left(\mathrm{S}_{\mathrm{n}, \mathrm{tb}}\right)$, the local thermal stress range $\left(\mathrm{S}_{\mathrm{p}, \mathrm{t}}\right)$, and the total stress range less the contribution of thermal bending and local thermal stresses $\left(\mathrm{S}_{\mathrm{p}-\mathrm{lt}-\mathrm{tb}}\right)$. The plasticity-adjusted alternating stress amplitude $\left(\mathrm{S}_{\mathrm{alt}}\right)$ is then determined by Eq. (2).

$$
\begin{array}{r}
S_{a l t}=\frac{1}{2}\left[K_{e}^{N-779} S_{p-t b-l t}+K_{v}^{N-779} S_{l t}\right. \\
\left.+K_{v}^{N-779} K_{n}^{N-779} S_{t b}\right]
\end{array}
$$

where $\mathrm{K}_{\mathrm{e}}^{\mathrm{N}-779}$ is equivalent to the Appendix XIII-3450 $\mathrm{K}_{\mathrm{e}}$ (Eq. 1); $\mathrm{K}_{\mathrm{V}}{ }^{\mathrm{N}-779}$ is a Poisson's ratio correction factor, defined by Eq. (3), which varies as a function of $S_{n, t b}$ and $S_{p, l t}$ :

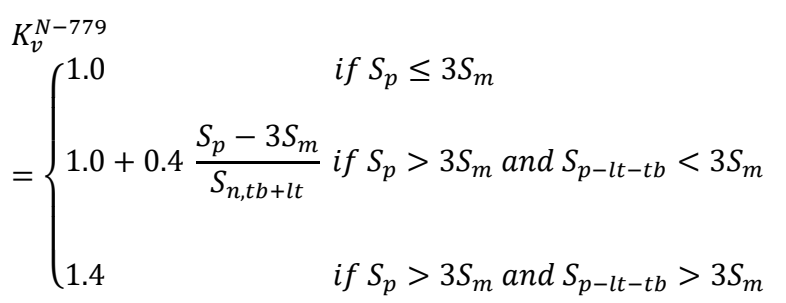


$\mathrm{K}_{\mathrm{n}}^{\mathrm{N}-779}$ is a notch plasticity correction factor defined by Eq. (4):

$$
\begin{aligned}
& K_{n}^{N-779} \\
& = \begin{cases}1.0 & \text { if } S_{p-l t} \leq 3 S_{m} \\
1.0+\left[\left(\frac{S_{p-l t}}{S_{n}}\right)^{\frac{1-n}{1+n}}-1\right] \frac{S_{p-l t}-3 S_{m}}{S_{p-l t}} & \text { if } S_{p-l t}>3 S_{m}\end{cases}
\end{aligned}
$$

where $S_{p-1 t} / S_{n}$ is the numerical stress concentration factor $(\mathrm{SCF})$ and thus $\mathrm{K}_{\mathrm{n}}{ }^{\mathrm{N}-779}$ is applicable only to FE models which do not include a detailed refinement of local discontinuities. Otherwise, a $\mathrm{K}_{\mathrm{n}}{ }^{\mathrm{N}-779}$ value of unity is applicable. In Eq. (2), each subfactor is multiplied to the range of the unique components of each stress tensor, before forming the stress intensity of the result.

\section{RANGANATH'S METHOD}

A recent proposal by Ranganath et al [4] is currently under consideration by the ASME Working Groups on Design Methodology (WGDM) and Fatigue Strength (WGFS) for inclusion as an ASME Code Case (Case 17-225). The approach is based partially on the methodology outlined in Welding Research Council (WRC) Bulletin 361 [5], and proposes a weighted average correction factor, $\mathrm{K}_{\mathrm{e}}{ }^{\mathrm{R}}$, defined by Eq. (5):

$$
K_{e}^{R}=K_{t h}^{R}(1-R)+K_{e} R
$$

where $K_{e}$ is equivalent to Appendix XIII-3450, $K_{t h}{ }^{R}$ is set equal to the maximum possible Poisson's ratio correction factor of 1.4 assuming fully-plastic behavior, and $R$ defines the contribution of thermal membrane stresses to the linearized stress range:

$$
\begin{gathered}
K_{t h}^{R}=\frac{1-v_{e}}{1-v_{p}} \cong \frac{0.7}{0.5}=1.4 \\
R=\frac{S_{n-t b}}{S_{n}}
\end{gathered}
$$

Based on the results of a parametric study, Reinhardt [6] identified the potential for $\mathrm{K}_{\mathrm{e}}^{\mathrm{R}}$ to be non-conservative for large thermal bending combined with significant notch effects. Ranganath's original proposal has since been revised to include a Neuber notch correction factor, $\mathrm{K}_{\mathrm{n}}{ }^{\mathrm{R}}$, defined by Eq. (8), which is intended to account for additional plastic strain concentration at local discontinuities under globalized plasticity:

$$
K_{n}^{R}=K_{T}^{\frac{1-n}{1+n}}
$$

The final definition of $\mathrm{K}_{\mathrm{e}}{ }^{\mathrm{R}}$ is given by Eq. (9)

$$
K_{e}^{R}=\left\{\begin{array}{cc}
1.0 & \text { if } S_{n} \leq 3 S_{m} \\
\min \left[K_{e} R+K_{t h}^{R}(1-R) K_{n}^{R}, K_{e}\right] & \text { if } 3 S_{m}<S_{n} \leq 3 m S_{m} \\
\min \left[K_{e} R+K_{t h}^{R}(1-R) K_{n}^{R}, \frac{1}{n}\right] & \text { if } S_{n}>3 m S_{m}
\end{array}\right.
$$

The $\mathrm{K}_{\mathrm{e}}{ }^{\mathrm{R}}$ formulation was developed with plant life extension in mind, and has the advantage that $\mathrm{S}_{\mathrm{n}-\mathrm{tb}}$ is usually already present in standard fatigue tables.

\section{OUTLINE AND SCOPE OF ASSESSMENT}

This section provides information on the scope of the performance assessment, the FE models considered, and details of the analysis methods employed. The different code-based $\mathrm{K}_{\mathrm{e}}$ factors considered in the assessment are summarized in Table 1. This included the ASME III $\mathrm{K}_{\mathrm{e}}$ factors already discussed, and a variety of alternative $\mathrm{K}_{\mathrm{e}}$ factors adopted by other nuclear (e.g RCC-M and JSME), and conventional (e.g. ASME VIII-2, EN13445 ) design and construction codes. For further details on the technical basis of each approach, the reader is referred to the applicable reference(s) provided in the final column.

A series of $\mathrm{FE}$ models were used to benchmark the predictive capability of the Code plasticity correction factors when compared to the results of elastic-plastic analysis. The FE models considered in this paper are: the stepped pipe discussed in Jones et al [7]; three generic PWR coolant line piping nozzles, including the main coolant line nozzle described by Benchmark Problem 2 in Part 2a of the CORDEL Non-Linear Analysis Design Rules Report [8]; a PWR vessel nozzle with an attached thermal sleeve as described in Hübel's Simplified Theory of Plastic Zones book [9]; the large tapered nozzle-in-vessel described in Kobayashi and Yamada [10]; the Y-piece vessel skirt support described in Kasahara [11]; and a parametric study conducted on a series of thin-walled cylinders containing a semicircular notch. Figure 1-5 show the structural geometry, mesh, and stress classification line (SCL) locations for the respective FE models. For the notched cylinder parametric study described in Figure 6, five semi-circular notch sizes were investigated with radius of curvature, $\rho$, equal to $5,2.5,1.25,0.625$, and 0.3125 $\mathrm{mm}$. Three different applied thermal gradients were also considered: linear axial, linear radial, and parabolic (shock) radial. Since it is more representative of plant loading, only the results for the radial thermal shock are considered here.

The objective of the assessment was to determine the plasticity correction factors for each of the FE models by performing elastic-plastic analysis for a range of applied thermal transients. The FE-derived correction factors were then compared with the code $\mathrm{K}_{\mathrm{e}}$ factors determined from the corresponding elastic analysis.

All components considered in this paper were of Type 304 austenitic stainless steel (SS), and whose temperature-dependent mechanical and thermal properties were obtained from ASME Section II, Part D [12]. The elastic and elastic-plastic FE analyses were conducted using Abaqus [13], and the fatigue analysis was 
performed using a Python-based Abaqus plug-in developed by the author.

\section{Plastic Analysis Methodology}

A number of approaches have been proposed in the technical literature for determination of $\mathrm{K}_{\mathrm{e}}$ using elastic-plastic FE analysis in combination with the cyclic stress-strain curve of the relevant material. These approaches fall into three general categories: a) Simplified monotonic analysis of $\mathrm{K}_{\mathrm{e}}$ using an isotropic hardening rule; b) The Twice-Yield Method proposed by Kalnins [14]; and c) Sequential cycle-by-cycle analysis using a kinematic hardening rule.

For all models, the cyclic stress-strain behaviour was described using the Chaboche non-linear kinematic hardening model [15]. The Chaboche model parameters were obtained through non-linear curve fitting to Type 304 SS stabilized cyclic stress-strain data, including that presented in NUREG/CR-5704 [16], for strain amplitudes up to $1.5 \%$. In the ASME Code, the threshold stress range beyond which a plasticity correction is required is defined by $3 \mathrm{~S}_{\mathrm{m}}$, and hence the threshold stress amplitude is half this value at $1.5 \mathrm{~S}_{\mathrm{m}}$. To maintain consistency with the elastic DBA approach, the yield offset stress for the temperature-dependent hardening curves was defined to match closely the limit of $1.5 \mathrm{~S}_{\mathrm{m}}$ at temperature.

In performing the elastic-plastic FE analysis, ten sequential cycles were simulated for all thermal transients considered. This was judged to be acceptable based on industry best practices.

\section{Effective Multiaxial Strain Range}

An 'effective strain' approach was utilized in this study and uses a uniaxial equivalent strain measure to characterize fatigue damage under multiaxial loading. One important requirement of any selected strain measure is that it must reduce to give the same state of strain in the case of a uniaxially loaded test specimen. ASME III, Appendix XIII-2400 currently prescribes the use of the numerically maximum principal total strain range, $\Delta \varepsilon_{\text {eff }} \mathrm{MP}$, when performing fatigue analysis on a plastic basis. However, $\Delta \varepsilon_{\text {eff }}{ }^{\mathrm{MP}}$ has been shown by several authors to be inadequate for evaluating fatigue under multiaxial states of stress [17]-[19].

This study used the effective strain measure proposed by Norman Dowling [20]. Dowling's strain range is based on the von Mises criterion and is shown by Eq. (10):

$$
\Delta \varepsilon_{e f f}^{\text {Dowling }}=\Delta \varepsilon_{V M}^{e}+\Delta \varepsilon_{V M}^{p}
$$

where $\Delta \varepsilon_{v M}{ }^{e}$ is the von Mises equivalent elastic strain range calculated by either of Eqs. (11) or (12):

$$
\Delta \varepsilon_{V M}^{e}=\frac{\sqrt{2}}{2 \cdot(1+v)} \sqrt{\begin{array}{c}
\left(\Delta \varepsilon_{1}^{e}-\Delta \varepsilon_{2}^{e}\right)^{2}+\left(\Delta \varepsilon_{2}^{e}-\Delta \varepsilon_{3}^{e}\right)^{2} \\
+\left(\Delta \varepsilon_{3}^{e}-\Delta \varepsilon_{1}^{e}\right)^{2}
\end{array}}
$$

\section{OR}

$$
\Delta \varepsilon_{V M}^{e}=\frac{1}{E \cdot \sqrt{2}} \sqrt{\begin{array}{c}
\left(\Delta \sigma_{1}-\Delta \sigma_{2}\right)^{2}+\left(\Delta \sigma_{1}-\Delta \sigma_{2}\right)^{2} \\
+\left(\Delta \sigma_{1}-\Delta \sigma_{2}\right)^{2}
\end{array}}
$$

where $\mathrm{E}$ is the modulus of elasticity at the mean temperature of the cycle; and $\Delta \varepsilon \mathrm{VM}^{\mathrm{p}}$ is the von Mises equivalent plastic strain range calculated by Eq. (13).

$$
\Delta \varepsilon_{V M}^{p}=\frac{\sqrt{2}}{3} \sqrt{\begin{array}{c}
\left(\Delta \varepsilon_{1}^{p}-\Delta \varepsilon_{2}^{p}\right)^{2}+\left(\Delta \varepsilon_{2}^{p}-\Delta \varepsilon_{3}^{p}\right)^{2} \\
+\left(\Delta \varepsilon_{3}^{p}-\Delta \varepsilon_{1}^{p}\right)^{2}
\end{array}}
$$

The choice of whether to use Eq. (11) or (12) to determine $\Delta \varepsilon_{V M}{ }^{\mathrm{e}}$ is at the discretion of the analyst, though Eq. (11) was used here as it is technically more accurate. $\Delta \varepsilon_{\text {eff }}{ }^{\text {Dowling }}$ was calculated between the extreme (peak-valley) time points of the final cycle. The implied correction factor, $\mathrm{K}_{\mathrm{e}}^{\mathrm{FEA}}$, is then determined by Eq. (14):

$$
K_{e}^{F E A}=\frac{\Delta \varepsilon_{\text {eff }}^{\text {Dowling }}}{\Delta \varepsilon_{\text {eff }}^{\text {elastic }}}
$$

where $\Delta \varepsilon_{\text {eff }}^{\text {elastic }}$ is the Dowling's strain range calculated by elastic analysis.

It is acknowledged that the ASME III design limits are based on the Tresca hypothesis, however the use of a Tresca-based elastic strain measure would not be appropriate in this case, since some loadings were considered other than equi-biaxial, and thus the differences between the von Mises and Tresca strain intensities were not always negligible. Adopting the above approach therefore ensures that the elastic and elastic-plastic strain ranges are always directly compatible. More importantly, it also ensures consistency across both the FEA and correction factor derivation, such that the FE-derived plastic strains used as input to the fatigue analysis are also reliant on the von Mises yield criterion. To achieve consistency using a Tresca-based strain measure would require the use of a Tresca yield criterion in the $\mathrm{FE}$ analysis, which can pose numerical stability problems as the Tresca yield surface contains singularities and is therefore not continuously differentiable. The determination of $\mathrm{K}_{\mathrm{e}}$ based on the von Mises criteria was therefore deemed most reasonable.

\section{Elastic DBA Considerations}

A consistent approach to performing codified elastic fatigue analysis was adopted for all $\mathrm{FE}$ models to enable ready comparison of results. The ASME III Appendix XIII-3450 $\mathrm{K}_{\mathrm{e}}$ factor is a function of $S_{n}$, which must be obtained from stress linearization. $\mathrm{S}_{\mathrm{n}}$ varies as a function of both applied loading and section properties (shape, thickness, etc.) and has the potential to be out-of-phase with $\mathrm{S}_{\mathrm{p}}$, particularly for thick-walled components. Thus, to ensure that the maximum value of $\mathrm{K}_{\mathrm{e}}$ is captured for $\mathrm{S}_{\mathrm{n}}$-based corrections, $\mathrm{K}_{\mathrm{e}}$ was calculated based on the extremes of $S_{n}$. Similarly, for $S_{p}$-based corrections, $K_{e}$ was 
calculated based on the extremes of $\mathrm{S}_{\mathrm{p}}$. A combined approach was taken for complex $\mathrm{K}_{\mathrm{e}}$ factors such as CC N-779, whereby the stress tensor ranges corresponding to maximum $S_{n}$ were input to Eqns. (2)-(4), and subsequently an equivalent $\mathrm{K}_{\mathrm{e}}$ value was determined from Eqn. (5) based on maximum $S_{p}$. In all cases where a subtraction of two or more stress ranges was required, the subtraction was performed on a component basis followed by forming the stress intensity of the result.

A very important prerequisite for applying the $\mathrm{K}_{\mathrm{e}}$ factor is given by ASME III Appendix XIII-3450 (a), which states that the range of primary-plus-secondary stress, $\mathrm{S}_{\mathrm{n}}$, less the contribution from thermal bending stresses, $S_{n, t b}$, must remain within the elastic range. In other words, only $S_{n, t b}$ and $S_{p, t t}$ are permitted to exceed $3 \mathrm{~S}_{\mathrm{m}}$. Any load combinations which were found to violate this precondition were discounted from the results.

Stress linearization was performed for all unique stress components using a Python class. In all cases, $\mathrm{K}_{\mathrm{e}}$ was calculated based on the value of $\mathrm{S}_{\mathrm{m}}$ corresponding to the maximum temperature of the cycle. The calculated Code $\mathrm{K}_{\mathrm{e}}$ factors therefore represent the most conservative possible value.

\section{DISCUSSION OF ELASTIC-PLASTIC FEA RESULTS}

The results amalgamated from all FE models are shown in Figure 7 alongside the ASME III Appendix XIII-3450 $\mathrm{K}_{\mathrm{e}}$ factor for comparison. To compare the performance of the Code $\mathrm{K}_{\mathrm{e}}$ methods for each FE model, the Code $\mathrm{K}_{\mathrm{e}}$ factors are plotted against the FE-derived correction factors as shown in Figures 812. The black line represents the condition where the Code $\mathrm{K}_{\mathrm{e}}$ factor is equal to the FE-derived $\mathrm{K}_{\mathrm{e}}$ factor. Points situated below this line indicate that the Code $\mathrm{K}_{\mathrm{e}}$ correction underpredicts the strain range determined from elastic-plastic FE analysis. The red line denotes the ASME Code limit of $3 \mathrm{~S}_{\mathrm{m}}$, which represents the threshold beyond which the Code plasticity correction is applied.

\section{ASME III Appendix XIII-3450}

An inherent assumption in the ASME III Code methodology is that peak strain concentration cannot occur for $\mathrm{S}_{\mathrm{n}}<3 \mathrm{~S}_{\mathrm{m}}$. Whilst this assumption is legitimate for the simple configurations considered by Langer, it is not strictly true when extending to more complex structures and loading conditions. Even in situations where a plastic zone is limited in its extent, as in the case of a thermal shock or local discontinuity, $\mathrm{K}_{\mathrm{e}}$ will still be greater than 1.0 based on Langer's original definition. As a consequence the Appendix XIII- $3450 \mathrm{~K}_{\mathrm{e}}$ factor was found to be moderately non-conservative for $\mathrm{S}_{\mathrm{n}}$ slightly above the $3 \mathrm{~S}_{\mathrm{m}}$ limit. Naturally, it is also non-conservative below the $3 \mathrm{~S}_{\mathrm{m}}$ limit, however in this situation the XIII-2500 Poisson's ratio correction would apply, which could potentially produce an overall conservative result. In particular, in this study it was found that in the presence of a notch, the ASME XIII- $3450 \mathrm{~K}_{\mathrm{e}}$ factor can underpredict the elastic-plastic strain range by up to $40 \%$.

In contrast, as $\mathrm{S}_{\mathrm{n}}$ increases beyond $3 \mathrm{~S}_{\mathrm{m}}, \mathrm{K}_{\mathrm{e}}$ quickly becomes very conservative. For un-notched sections subjected to thermal shock conditions, the $\mathrm{K}_{\mathrm{e}}$ maximum value of 3.33 was generally found to be a factor of $2.2-3.0$ larger than the corresponding value of $\mathrm{K}_{\mathrm{e}}{ }^{\mathrm{FEA}}$. For the notched cylinder, $\mathrm{K}_{\mathrm{e}}$ was still found to be overconservative by a factor of $1.8-2.4$.

Whilst the Appendix XIII- $3450 \mathrm{~K}_{\mathrm{e}}$ factor is straightforward to apply, its practicality is significantly outweighed by its aforementioned conservatism. Due to the non-linearity of the design fatigue curves in the low-cycle regime, the use of the XIII-3450 $\mathrm{K}_{\mathrm{e}}$ factor can very easily produce a cumulative usage factor (CUF) over an order of magnitude higher than elasticplastic FEA, which could be unacceptable in the current industry climate.

\section{Code Case N-779}

CC N-779 was found to perform well for the stepped pipe FE model, predicting modestly conservative corrections for $\mathrm{S}_{\mathrm{n}} \leq$ $5.5 \mathrm{~S}_{\mathrm{m}}$. For higher $\mathrm{S}_{\mathrm{n}}, \mathrm{CC} \mathrm{N}-779$ was slightly non-conservative up to a maximum of $12 \%$. This aligned closely with the results obtained independently by Emslie et al [19]. In general CC N779 did not perform as well for the PWR nozzle FE models, producing underpredictions of $10-25 \%$ for $\mathrm{S}_{\mathrm{n}} \leq 10 \mathrm{~S}_{\mathrm{m}}$. This was observed particularly for the crotch corner and pipe-to-nozzle juncture. For the thermal sleeve and Y-piece FE models, CC N779 produced more conservative results. This was attributed to the higher value of $S_{n, t m}$ due to the presence of a larger axial thermal gradient, which results in a greater weighting being applied to the more conservative Appendix XIII-3450 $\mathrm{K}_{\mathrm{e}}$ factor. In the case of the notched cylinder FE model, CC N-779 was found to produce non-conservative results up to around $30 \%$ across all notch sizes. Since the FE models included discretization of the notch region, $\mathrm{K}_{\mathrm{n}}^{\mathrm{N}-779}$ is equal to unity, with only the Poisson's ratio correction factor, $\mathrm{K}_{\mathrm{v}}{ }^{\mathrm{N}-779}$ being applicable. However, $\mathrm{K}_{\mathrm{v}}^{\mathrm{N}-779}$ was found to be insufficient to account for the additional concentration of peak strain at the notch root. The modification to $\mathrm{K}_{\mathrm{v}}^{\mathrm{N}-779}$ proposed by Lang et al [21] was also considered and was typically found to increase the conservatism of CC N-779 by up to $10 \%$.

CC N-779 is not as straightforward to apply as Appendix XIII-3450. Firstly, it requires that stresses arising due to mechanical and thermal loads are obtained separately. This alone is not necessarily an issue, since this is still a necessary step to satisfy the requirements of Appendix XIII-3450 (a) as a prerequisite to applying a $\mathrm{K}_{\mathrm{e}}$ factor. However, CC N-779 does require calculation of several stress quantities, e.g. $S_{\text {p-lt-tb }}$ and $\mathrm{S}_{\mathrm{lt}+\mathrm{tb}}$, which are not typically reported in standard fatigue tables. This has generally precluded application of CC N-779 for plant license extension, since it necessitates a costly re-run of prior FE analyses to obtain these missing quantities. However, implementation of CC N-779 can be reliably automated using programming methods, minimizing the additional effort involved.

\section{Ranganath's Method}

Ranganth's method was found to produce conservative results for almost all cases considered. For the stepped pipe FE model, $\mathrm{K}_{\mathrm{e}}^{\mathrm{R}}$ was generally found to be $10-30 \%$ conservative for $\mathrm{S}_{\mathrm{n}}>3 \mathrm{~S}_{\mathrm{m}}$, showing a decreasing trend which aligned closely with the RCC-M thermal-plastic correction factor, $\mathrm{K}_{\mathrm{e}}^{\text {ther }}$. This is to be 
expected since both approaches share the same technical basis outlined in WRC-361 [5]. For the PWR nozzle FE models, $\mathrm{K}_{\mathrm{e}}{ }^{\mathrm{R}}$ showed a similar trend in conservatism to the stepped pipe, albeit with slightly higher scatter depending on the relative proportions of $\mathrm{S}_{\mathrm{n}, \mathrm{tb}}$ and $\mathrm{S}_{\mathrm{n}, \mathrm{tm}}$ at the assessment location. Similarly to CC N$779, \mathrm{~K}_{\mathrm{e}}{ }^{\mathrm{R}}$ also showed greater conservatism for the $\mathrm{Y}$-piece model since $S_{n, t m}$ accounted for a larger proportion of $S_{n}$, thereby producing a larger value of $R$.

As previously mentioned, the value of $\mathrm{K}_{\mathrm{e}}{ }^{\mathrm{R}}$ in this paper for all FE models initially did not consider the recently revised notch factor, $\mathrm{K}_{\mathrm{n}}{ }^{\mathrm{R}}$. For the notch cylinder $\mathrm{FE}$ models, $\mathrm{K}_{\mathrm{e}}{ }^{\mathrm{R}}$ was calculated with and without $\mathrm{K}_{\mathrm{n}}{ }^{\mathrm{R}}$ to examine further the observations of Reinhardt [6] under more realistic loading conditions. As shown by Figure $12, \mathrm{~K}_{\mathrm{e}}{ }^{\mathrm{R}}$ appears to coincide quite closely with the results obtained from elastic-plastic FE analysis when $K_{n}{ }^{R}$ is excluded. For $S_{n}>3 S_{m}, K_{e}{ }^{R}$ was found to produce results that were modestly conservative by up to $50 \%, 15 \%$, and $7 \%$ respectively for the three largest notch sizes considered in this study $(\rho=5,2.5,1.25 \mathrm{~mm}) . \mathrm{K}_{\mathrm{e}}^{\mathrm{R}}$ was however found to produce slightly non-conservative results up to $9 \%$ and $19 \%$ respectively for the two smallest notch sizes $(\rho=0.625,0.3125$ $\mathrm{mm})$.

This was mainly attributed to the fact that $S_{n}$ is not well suited as a characteristic parameter when assessing local discontinuities. $S_{p}$ increases significantly at the notch root for decreasing $\rho$, while the value of $S_{n}$ remains almost constant. In addition, it was found that the magnitude of $S_{n, t m}$ also decreased with decreasing $\rho$. This is especially significant as this resulted in lower values of $R$, and consequently a decreasing trend in $\mathrm{K}_{\mathrm{e}}{ }^{\mathrm{R}}$ despite an increase in $\mathrm{K}_{\mathrm{e}}{ }^{\mathrm{FEA}}$ at the notch root. Overall, without considering $\mathrm{K}_{\mathrm{n}}{ }^{\mathrm{R}}$, the higher conservatism of Ranganath's Method compared to CC N-779 is mainly due to its use of the maximum Poisson's ratio correction factor of 1.4, which produced more reasonable results. When $\mathrm{K}_{\mathrm{n}}{ }^{\mathrm{R}}$ described by Eqn. (8) is included, the conservatism of Ranganath's method relative to the results of elastic-plastic $\mathrm{FE}$ analysis increases considerably. For $\mathrm{S}_{\mathrm{n}}>>3 \mathrm{~S}_{\mathrm{m}}, \mathrm{K}_{\mathrm{e}} \mathrm{R}^{\mathrm{R}}$ is conservative by a factor of 1.3 -1.8 for all notch sizes when $\mathrm{K}_{\mathrm{n}}{ }^{\mathrm{R}}$ is included.

It was highlighted in a previous presentation given by the author [22] that there also exists the potential for some ambiguity in the final value of $\mathrm{K}_{\mathrm{e}}^{\mathrm{R}}$, depending on the subtraction methodology employed to calculate $S_{n-t b}$. As highlighted by Reinhardt [6], performing this subtraction on a component basis and forming the stress intensity of the result often produces different results when compared to subtracting stress intensities. This was found to be important, since adopting the latter approach was found to produce up to a $25 \%$ reduction in the value of $\mathrm{K}_{\mathrm{e}}^{\mathrm{R}}$, which often made the difference between a conservative and non-conservative prediction. This may warrant further engineering judgement for plants undergoing license extension, since existing fatigue tables often only present ranges in terms of stress intensities for a given load pair. For application to new designs, it is recommended to perform this subtraction on a component basis to eliminate possible ambiguity in the results.

\section{Plasticity Correction Factors from Other Codes}

A number of notable observations in the results obtained using $\mathrm{K}_{\mathrm{e}}$ factors from other Codes are discussed briefly here.

\section{$R C C-M$}

The results presented in this paper considered only cyclic thermal transients, and thus only the RCC-M thermal plastic correction factor, $\mathrm{K}_{\mathrm{e}}{ }^{\text {ther }}$, was applicable. $\mathrm{K}_{\mathrm{e}}^{\text {ther }}$ showed a very similar to trend to Ranganath's $\mathrm{K}_{\mathrm{e}}^{\mathrm{R}}$, producing results that were $10-40 \%$ conservative for the stepped pipe and PWR nozzle FE models. $\mathrm{K}_{\mathrm{e}}{ }^{\mathrm{R}}$ was however found to be significantly more conservative than $\mathrm{K}_{\mathrm{e}}{ }^{\text {ther }}$ for the Y-piece FE model. The reason for this is that $\mathrm{K}_{\mathrm{e}}^{\text {ther }}$ does not distinguish between membrane, bending, and peak stresses arising due to thermal effects, and implicitly assumes they behave as secondary stresses. In contrast, $\mathrm{K}_{\mathrm{e}}{ }^{\mathrm{R}}$ assumes $\mathrm{S}_{\mathrm{n}, \mathrm{tm}}$ to act as a primary stress, thereby requiring a larger correction. Thus, both approaches can be expected to deviate with increasing $S_{n, t m} / S_{n}$.

\section{$J S M E$}

As discussed by Asada and Nakamura [23], the JSME $\mathrm{K}_{\mathrm{e}}{ }^{\prime}$ was derived based on a series of elastic-plastic FE analyses conducted on representative components using simplified monotonic analysis with an elastic perfectly-plastic (EPP) material model. From the results it is clear that $\mathrm{K}_{\mathrm{e}}{ }^{\prime}$ is quite conservative for all models, which is largely attributed to its being derived based on EPP material properties. In contrast to other $\mathrm{S}_{\mathrm{n}}$-based $\mathrm{K}_{\mathrm{e}}$ factors, $\mathrm{K}_{\mathrm{e}}$ ' actually becomes more conservative with increasing $\mathrm{S}_{\mathrm{n}}$.

\section{JSME Code Case NC-CC-005}

The JSME Code Case NC-CC-005 on alternative design methodology by using elastic-plastic FE analysis for Class 1 vessels includes a correction factor, denoted $\mathrm{K}_{\mathrm{e}}$ ", which is a function of $\mathrm{S}_{\mathrm{p}}$ only. $\mathrm{K}_{\mathrm{e}}$ " was derived based on the same set of bounding EPP FE analysis results used to derive $K_{e}{ }_{e}$, but does not require stress linearisation. As shown by the results, $\mathrm{K}_{\mathrm{e}}$ " is always more conservative than $\mathrm{K}_{\mathrm{e}}{ }^{\prime}$, and also applies for $\mathrm{S}_{\mathrm{n}}<3 \mathrm{~S}_{\mathrm{m}}$ if $\mathrm{S}_{\mathrm{p}} \geq$ $3 \mathrm{~S}_{\mathrm{m}}$.

\section{PNAE G-7-086-002}

The stress determination procedure of PNAE G-7-086-002 includes a procedure for estimation of inelastic strain using Glinka's approximation with a power-law stress-strain curve. The correction factor appeared to fall between the JSME $\mathrm{K}_{\mathrm{e}}$ ' and $\mathrm{K}_{\mathrm{e}}$ " in terms of conservatism. A prerequisite for applying the procedure is that $S_{n}$ does not exceed four times the cyclic proportional limit stress.

R5

Two corrections based on total surface stresses are described in R5 Vol.2/3 Appendix A7 Enhancement of Strain Range due to Plasticity and Creep: a Neuber correction to account for the occurance of plasticity, and a volumetric correction to account for additional strain enhancement due to Poisson's ratio effects. The R5 Neuber methodology was found to be excessively 
conservative, in overall agreement with the conclusions drawn by other authors that Neuber's rule is not well suited to thermal loading [21]. On the other hand, applying the R5 volumetric correction factor but excluding the Neuber correction produced very reasonable results. This approach was generally conservative up to a maximum of $25 \%$ for unnotched assessment locations. The approach is also quite useful from a practical standpoint as it does not involve stress linearization, and only requires that the intersection of the Neuber hyperbola with the cyclic stress-strain curve be determined a priori.

\section{ASME VIII-2, Section 5.5.3}

The ASME VIII-2, Section 5.5.3 $\mathrm{K}_{\mathrm{e}}$ factor is essentially equivalent to the ASME III, Appendix XIII-3450 $\mathrm{K}_{\mathrm{e}}$ factor, with the only difference being that the former is based on Von Mises theory, with the latter being based on Tresca.

\section{ASME VIII-2, Annex 5-C}

The ASME VIII-2, Annex 5-C $\mathrm{K}_{\mathrm{e}}$ factor has a similar form to $\mathrm{CC} \mathrm{N-779.} \mathrm{The} \mathrm{former} \mathrm{approach} \mathrm{does} \mathrm{however} \mathrm{possess} \mathrm{a} \mathrm{more}$ conservative Poisson's ratio correction factor, which tends to a maximum value of 1.6, compared to 1.4 for CC N-779. Overall, ASME VIII-2, Annex 5-C was found to be more accurate than CC N-779.

\section{AD 2000-Merkblatt}

Within the German conventional pressure vessel code, AD 2000-Merkblatt S2, a correction denoted $K_{v}$ is described in Section 6.2 for application to thermal loadings "through the material thickness", and varies as a function of $\mathrm{S}_{\mathrm{p}}$ only. $\mathrm{K}_{\mathrm{v}}$ was found to be both straightforward to apply and reasonably accurate (often within 10\%) for unnotched assessment locations. $\mathrm{K}_{\mathrm{v}}$ was found to be slightly non-conservative for the notched cylinder FE study, but still performed better than more complex $\mathrm{K}_{\mathrm{e}}$ factors such as CC N-779 with significantly less effort involved.

\section{EN-13445 Annex 18}

Annex 18, Detailed Assessment of Fatigue Life within the conventional European pressure vessel code, EN-13445, also includes a plasticity correction factor for thermal loadings, $\mathrm{K}_{\mathrm{v}}$, which varies only as a function of linearised stress, $\mathrm{S}_{\mathrm{n}}$. The EN$13445 \mathrm{~K}_{\mathrm{v}}$ factor was generally found to produce the least conservative results of the different factors considered. It is concluded to be insufficient to account for strain concentration due to Poisson's ratio effects.

\section{EMPIRICAL FE-DERIVED CORRECTION FACTOR $\left(\mathbf{F}_{\mathrm{g}}\right)$}

The role of a plasticity correction factor is to provide a reasonable approximation of the local inelastic response whilst being straightforward to apply. A good balance of accuracy and practicality is therefore needed. The trend in $\mathrm{K}_{\mathrm{e}}^{\mathrm{FEA}}$ results observed in Figure 7 clearly shows that a great variety of nuclear power plant structures exhibit a similar inelastic structural response under cyclic thermal loading. The technical basis for this phenomenon relates to elastic follow-up and is to be explored in a future paper. Nonetheless, using the elastic-plastic FE results presented in this paper, it was desirable to derive an alternative approach to performing the plasticity correction, which was modestly bounding, expressed in a simple format, and equally applicable to both notched and un-notched sections. The proposed approach is described in terms of a correction factor, $F_{g}$, which is itself a function of two other correction factors, $F_{p}$, and $F_{e} . F_{p}$ is a surface plasticity correction factor, described by Eq. (14) and is based on a power-law fit to $S_{p}$, which accounts for enhancement of strain due to Poisson's ratio effects and strain redistribution at local discontinuities. $F_{\mathrm{e}}$ is a sectional plasticity correction factor, described by Eq. (15) and is based on a plateau curve fit to $S_{n}$, which accounts for strain concentration under net section plasticity, and fulfills the intended role of the original ASME Code $\mathrm{K}_{\mathrm{e}}$ factor. $\mathrm{F}_{\mathrm{g}}$ is calculated by Eq. (16) as the maximum value of either $F_{p}$ or $F_{e}$, and is used to correct the alternating stress amplitude, $\mathrm{S}_{\mathrm{a}}$, for input to the fatigue design curve.

$$
\begin{gathered}
F_{p}=\left\{\begin{array}{c}
1.0 \text { if } S_{p}<3 S_{m} \\
0.708 \cdot\left(\frac{S_{p}}{S_{m}}\right)^{0.318} \quad \text { if } S_{p} \geq 3 S_{m}
\end{array}\right. \\
F_{e}=\left\{\begin{array}{c}
1.0 \text { if } S_{n}<3 S_{m} \\
\frac{2.344 \cdot S_{n} / S_{m}}{3.304+S_{n} / S_{m}} \text { if } S_{n} \geq 3 S_{m}
\end{array}\right. \\
F_{g}=\max \left[F_{p}, F_{e}\right]
\end{gathered}
$$

Whilst $F_{e}$ is strictly applicable for $S_{n}$ exceeding $3 S_{m}, F_{p}$ is applicable whenever yielding on the surface of the component is conceded, irrespective of the magnitude of $\mathrm{S}_{\mathrm{n}}$. In this way, $\mathrm{F}_{\mathrm{p}}$ ensures that peak strain concentration is covered for both $\mathrm{S}_{\mathrm{n}}<$ $3 \mathrm{~S}_{\mathrm{m}}$, and at the transition where $\mathrm{S}_{\mathrm{n}}$ is equal to, or slightly exceeds $3 \mathrm{~S}_{\mathrm{m}}$. The performance of the proposed $\mathrm{F}_{\mathrm{g}}$ factor is shown by Figure 13, and was found to produce consistently conservative corrections across all FE models. This conservatism was limited at most to $40 \%$ and $50 \%$ respectively for notched and unnotched assessment locations.

Overall, this approach was found to be useful since $S_{p}$ and $S_{n}$ are readily available without the need to separate the mechanical and thermal stress contributions. This also eliminates the aforementioned potential for error arising from subtracting stress ranges. It should be emphasised however that the $F_{g}$ derivation described here has only been acceptably demonstrated for cases where cyclic stresses arise predominantly due to thermal loads. Further work may be necessary to ensure that $F_{g}$ remains reliable in scenarios where combined cyclic loading is significant.

\section{DISCUSSION}

Looking to the future, it is expected that more accurate plastic design methods will see more routine application in civil nuclear safety cases given the rate of technological progress in recent decades. However, in the design of new build plants, 
improvements in accuracy must often be tempered with a great deal of pragmatism, owing mainly to time and budget constraints. In this context, improved plasticity correction factors offer an acceptable compromise between accuracy and practicality, and in the authors' opinion are expected to remain the most utilized approach in fatigue design of nuclear pressure vessels for the foreseeable future.

Based on the results presented in this paper, Ranganath's proposed $\mathrm{K}_{\mathrm{e}}^{\mathrm{R}}$ factor represents a considerable improvement over the current ASME III Appendix XIII-3450 $\mathrm{K}_{\mathrm{e}}$ factor. It was also found to be easier to apply and produced more consistent results than Code Case N-779. One could argue that the basis for inclusion or otherwise of the notch factor, $\mathrm{K}_{\mathrm{n}}{ }^{\mathrm{R}}$, is a matter of Code interpretation. One interpretation is that the role of $K_{e}$ is to preclude the initiation of surface cracks at local hot spots, though this seems unrealistic. In the authors' interpretation, the intention of the Code $\mathrm{K}_{\mathrm{e}}$ factor is to preclude the formation of structurally significant cracks arising due to gross section plastic cycling. This is consistent with Langer's original definition of $\mathrm{K}_{\mathrm{e}}$. The additional application of $\mathrm{K}_{n}{ }^{\mathrm{R}}$ could therefore be seen as excessively pessimistic for local discontinuities which typically exhibit a steep strain gradient. The argument here is that even if crack nucleation were conceded on the surface, this could very well be offset by the sharp decay in the crack driving force with increasing crack penetration. Nonetheless, even when $\mathrm{K}_{\mathrm{n}}{ }^{\mathrm{R}}$ was included, the resulting value of $\mathrm{K}_{e}{ }^{\mathrm{R}}$ was still considerably less pessimistic than the Appendix XIII- $3450 \mathrm{~K}_{\mathrm{e}}$ factor. Overall, the evidence presented in this paper for austenitic stainless steel strongly supports the inclusion of $\mathrm{K}_{\mathrm{e}}{ }^{\mathrm{R}}$ within a future Code Case.

It is however important to acknowledge that the overall process for determination of $\mathrm{K}_{\mathrm{e}}$ from elastic-plastic FE analysis, as well as the judgement of Code $\mathrm{K}_{\mathrm{e}}$ factors described in this paper necessarily involves a number of engineering assumptions which have a direct effect on the margin inherent in both calculations. Analyst judgement on the choice of stress methods and input material properties are therefore crucially important to understanding the conservatisms 'built-in' to the final value of $\mathrm{K}_{\mathrm{e}}$. The reader is referred to the useful discussion by Emslie et al [19] for further information on these factors.

One overarching issue is that there does not appear to exist a globally recognized (or 'harmonised') approach to determining $\mathrm{K}_{\mathrm{e}}$ by elastic-plastic analysis. This is not helped by the fact that several C\&S (including ASME III) prescribe neither cyclic stress-strain curves, nor any guidance on selection of an appropriate cyclic plasticity model. Others such as the JSME Code Case NC-CC-005 [24] do allow for determination of $\mathrm{K}_{\mathrm{e}}$ by elastic-plastic analysis, though the methodology is unusual and is only based on EPP material properties which is too pessimistic, especially for stainless steels. Due to the above concerns, the ongoing project of the CORDEL Mechanical Codes and Standards Task Force (MCSTF) addressing 'Non-linear Analysis Design Rules' includes within its scope the development of a set of recommended best practices for calculation of $\mathrm{K}_{\mathrm{e}}$ by elasticplastic analysis within a harmonised international Code Case managed by each participating Standard Development
Organisation (SDO). The project is anticipated to conclude with publication of the final report scheduled for the end of 2020.

\section{CONCLUSION}

A series of FE models of typical nuclear power plant structures were analysed using elastic and elastic-plastic analysis for a range of typical PWR thermal transients. The strain ranges determined from the FE analyses were compared to accurately determine the plasticity correction factors for each loading condition. The correction factors derived from elastic-plastic FE analysis were then used to critically evaluate the performance of the ASME III plasticity correction $\left(\mathrm{K}_{\mathrm{e}}\right)$ factors. A number of $\mathrm{K}_{\mathrm{e}}$ factors from other nuclear and non-nuclear codes were also evaluated and briefly discussed. An alternative correction factor, $F_{g}$, was derived from the elastic-plastic FE results and based on the total and linearized stress ranges. The $\mathrm{F}_{\mathrm{g}}$ approach was demonstrated to produce consistently conservative results whilst still being very straightforward to apply.

The $\mathrm{K}_{\mathrm{e}}{ }^{\mathrm{R}}$ approach outlined by Ranganath was evaluated and further discussed with consideration of the recently proposed notch correction factor, $K_{n}{ }^{R}$. Ranganath's $K_{e}{ }^{R}$ factor was found to perform consistently for all FE models considered, producing significantly less pessimistic results than the ASME III Appendix XIII-3450 $\mathrm{K}_{\mathrm{e}}$ factor, whilst retaining a modest level of conservatism. Based on the results presented in this paper, it was concluded that $\mathrm{K}_{\mathrm{e}}{ }^{\mathrm{R}}$ represents an acceptable alternative approach to the existing Appendix XIII-3450 procedure for application to austenitic stainless steels.

\section{REFERENCES}

[1] American Society of Mechanical Engineers, "ASME Boiler and Pressure Vessel Code, Section III, Division 1." ASME, 2017.

[2] B. F. Langer, "Design Basis for Pressure Vessels," in The William M. Murray Lecture, 1970.

[3] S. Adams, "An Alternative Simplified Elastic-Plastic Analysis Method Technical Support Document, ASME Code Correspondence," 2007.

[4] S. Ranganath and N. A. Palm, "PVP2017-66240: Alternative Approaches for ASME Code Simplified Elastic-Plastic Analysis," in ASME 2017 Pressure Vessels and Piping Conference, 2017.

[5] J. M. Grandemange, J. Heliot, J. Vagner, A. Morel, and C. Faidy, "WRC 361: Part 1, Improvements on Fatigue Analysis Methods for the Design of Nuclear Components Subjected to the French RCC-M Code," Shaker Heights, OH (USA), 1991.

[6] W. Reinhardt and S. Ranganath, "PVP2018-85146: Comparison of New Proposal for Simplified ElasticPlastic Analysis and Code Case N-779," in ASME 2018 Pressure Vessels and Piping Conference, 2018.

[7] D. P. Jones, J. E. Holliday, T. R. Leax, and J. L. Gordon, "PVP2004-2748: Analysis of a Thermal Fatigue Test of a Stepped Pipe," in ASME 2004 Pressure Vessels and Piping Conference, 2004, pp. 67-77.

[8] CORDEL Mechanical Codes and Standards Task Force 
(MCSTF), "Non-Linear Analysis Design Rules, Part 2a: Specification of Benchmarks on Nozzles under Pressure, Thermal, and Piping Loads," 2019.

[9] H. Hubel, Simplified Theory of Plastic Zones Based on Zarka's Method. Springer, 2017.

[10] K. Kobayashi and J. Yamada, "Estimation of Inelastic Behavior for a Tapered Nozzle in Vessel due to Thermal Transient Load using Stress Redistribution Locus Method," J. Solid Mech. Mater. Eng., vol. 6, no. 4, pp. 278-287, 2012.

[11] N. Kasahara, "Strain Concentration at Structural Discontinuities its Prediction based on Characteristics of Compliance Change in Structures," JSME Int. J., vol. 44, no. 3, pp. 354-361, 2001.

[12] American Society of Mechanical Engineers, "ASME BPVC Section II, Part D," 2015.

[13] Dassault Systèmes Simulia, "ABAQUS Version 6.14-5".

[14] A. Kalnins, "PVP2008-61397: Twice-Yield Method for Assessment of Fatigue Caused By Fast Thermal Transient According To 2007 Section Viii-Division 2," in Proceedings of ASME PVP 2008, 2008.

[15] J. L. Chaboche, "A review of some plasticity and viscoplasticity constitutive theories," Int. J. Plast., vol. 24, no. 10, pp. 1642-1693, 2008.

[16] O. K. Chopra, "NUREG/CR-5704: Effects of LWR Coolant Environment on Fatigue Design Curves of Austenitic Stainless Steels,” 1999.

[17] W. Reinhardt, "Strain Measures for Fatigue Assessment Using Elastic-Plastic FEA," in ASME 2005 Pressure Vessels and Piping Conference, 2005.

[18] T. Gilman and F. Ku, "PVP2016-63861: Environmentally-Assisted Fatigue Analysis Using a Strain-Based Approach," in ASME 2016 Pressure Vessels and Piping Conference, 2016.

[19] J. Emslie, C. Watson, and K. Wright, "PVP2014-28633: ASME III Fatigue Assessment Plasticity Correction Factors for Austenitic Stainless Steels," in ASME 2014 Pressure Vessels and Piping Conference, 2014.

[20] N. E. Dowling, Mechanical Behavior of Materials: Engineering Methods for Deformation, Fracture, and Fatigue, 4th Editio. Pearson, 2012.

[21] H. Lang, J. Rudolph, and R. Ziegler, "Performance study of Ke factors in simplified elastic plastic fatigue analyses with emphasis on thermal cyclic loading," Int. J. Press. Vessel. Pip., vol. 88, no. 8-9, pp. 330-347, 2011.

[22] D. Clarkson, D. Mackenzie, and C. Bell, "Performance Study of Design Code Rules for Simplified ElasticPlastic Fatigue Analysis of Nuclear Power Plant Pressure Vessels," in ESIA15 \& ISSI-2019 Joint Conference on Engineering Structural Integrity Assessment, 2019.

[23] S. Asada and T. Nakamura, "Simplified Elastic-Plastic Analysis Methods in the JSME Rules on Design and Construction," J. Environ. Eng., vol. 6, no. 4, pp. 753-
764, 2011.

[24] S. Asada, T. Hirano, T. Nagata, and N. Kasahara, "PVP2010-25525, Overview of Code Case on Alternative Design Methodology by Using ElasticPlastic Finite Element Analysis for Class 1 Vessels in the JSME Rules on Design and Construction," in $A S M E$ 2010 Pressure Vessels and Piping Conference, 2010.

[25] American Society of Mechanical Engineers (ASME), "Code Case N-779: Alternative Rules for Simplified Elastic-Plastic Analysis, Class 1 Section III, Division 1," Washington, DC (USA), 2009.

[26] S. Ranganath and N. Palm, "Alternative Approaches for ASME Code Simplified Elastic-Plastic Analysis," in NRC Public Meeting on EAF Research and Related ASME Activities, 2018.

[27] AFCEN, "RCC-M: Rules for Design and Construction of Nuclear Components from PWR Nuclear Islands," 2014.

[28] I. Saito and T. Shimakawa, "PVP2004-2690, Outline of the JSME (Japan Society of Mechanical Engineers) Rules on Design and Construction of Nuclear Power Plants.," in ASME 2004 Pressure Vessels and Piping Conference, 2004, vol. 480.

[29] Japanese Society of Mechanical Engineers (JSME), "Code Case NC-CC-005: Alternative Structural Evaluation Criteria for Class 1 Vessels Based on ElasticPlastic Finite Element Analysis (in Japanese)," 2008.

[30] GOST, "PNAE G-7-002-86: Rules of Strength Calculation for Equipment and Pipelines of Nuclear Power Plants," Moscow, Russia, 1987.

[31] EDF Energy Nuclear Generation, "R5, Assessment Procedures for the High Temperature Response of Structures, Revision 4," 2014.

[32] American Society of Mechanical Engineers, ASME BPVC, Section VIII, Division 2: Alternative Rules, 2015th ed. American Society of Mechanical Engineers, 2015.

[33] American Society of Mechanical Engineers (ASME), "ASME VIII-2, Annex 5-C: Alternative Plasticity Adjustment Factors and Effective Alternating Stress for Elastic Fatigue Analysis," 2007.

[34] “CEN/TC 54; EN 13445-3:2014/prA3:2015; 2015-10. Clause 18: "Detailed assessment of fatigue life", Annex NA: "Instructions for determining structural hotspot stress by finite element analysis using shell and brick elements"."

[35] G. Baylac and D. Koplewicz, "EN 13445: Unfired pressure Vessels, Background to the rules in Part 3 Design," 2004.

[36] Arbeitsgemeinschaft Druckbehälter (AD), “AD 2000Merkblatt, Special Cases, S2: Analysis for Cyclic Loading," 2004. 
Table 1. Summary of codified plasticity correction $\left(K_{e}\right)$ factors considered in this study

\begin{tabular}{|c|c|c|c|c|c|}
\hline Methodology & $\begin{array}{l}\text { Poisson's ratio } \\
\text { correction? }\end{array}$ & $\begin{array}{c}\text { Notch } \\
\text { correction? }\end{array}$ & $\begin{array}{c}\text { Stress } \\
\text { linearization? }\end{array}$ & $\begin{array}{c}\text { Stress } \\
\text { separation? }\end{array}$ & Reference(s) \\
\hline ASME III XIII-3450 & $x$ & $x$ & $\checkmark$ & $x$ & [1] \\
\hline ASME Code Case N-779 & $\checkmark$ & $\checkmark$ & $\checkmark$ & $\checkmark$ & [25], [3] \\
\hline Ranganath's Method & $\checkmark$ & $\sqrt{ } *$ & $\checkmark$ & $\checkmark$ & [4], [26] \\
\hline RCC-M & $\checkmark$ & $x$ & $\checkmark$ & $\checkmark$ & [5], [27] \\
\hline JSME & $x$ & $x$ & $\checkmark$ & $x$ & {$[23],[28]$} \\
\hline JSME Code Case NC-CC-05 & $x$ & $x$ & $x$ & $x$ & {$[29],[24]$} \\
\hline PNAEG-G7-002-86 & $x$ & $\checkmark$ & $x$ & $x$ & {$[30]$} \\
\hline R5 Volume $2 / 3$ & $\checkmark$ & $\checkmark$ & $x$ & $x$ & {$[31]$} \\
\hline ASME VIII-2, Section 5 & $x$ & $x$ & $\checkmark$ & $x$ & {$[32]$} \\
\hline ASME VIII-2, Annex 5C & $\checkmark$ & $\checkmark$ & $\checkmark$ & $\checkmark$ & {$[33]$} \\
\hline EN-13445, Annex 18 & $\checkmark$ & $x$ & $\checkmark$ & $\checkmark$ & {$[34],[35]$} \\
\hline AD 2000-Merkblatt S2 & $\checkmark$ & $x$ & $x$ & $\checkmark$ & [36] \\
\hline
\end{tabular}

${ }^{*}$ Ranganath's proposal has recently been revised to include a notch correction factor, $\mathrm{K}_{\mathrm{n}}{ }^{\mathrm{R}}$.

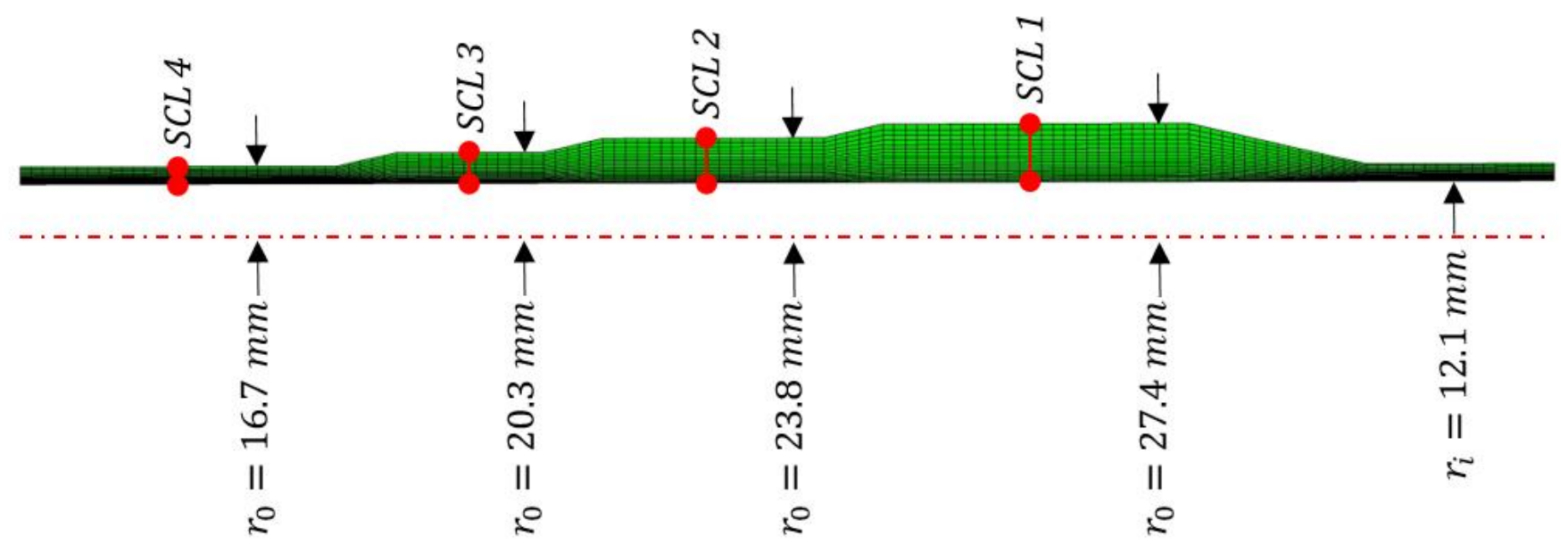

Figure 1. Stepped pipe FE model. 


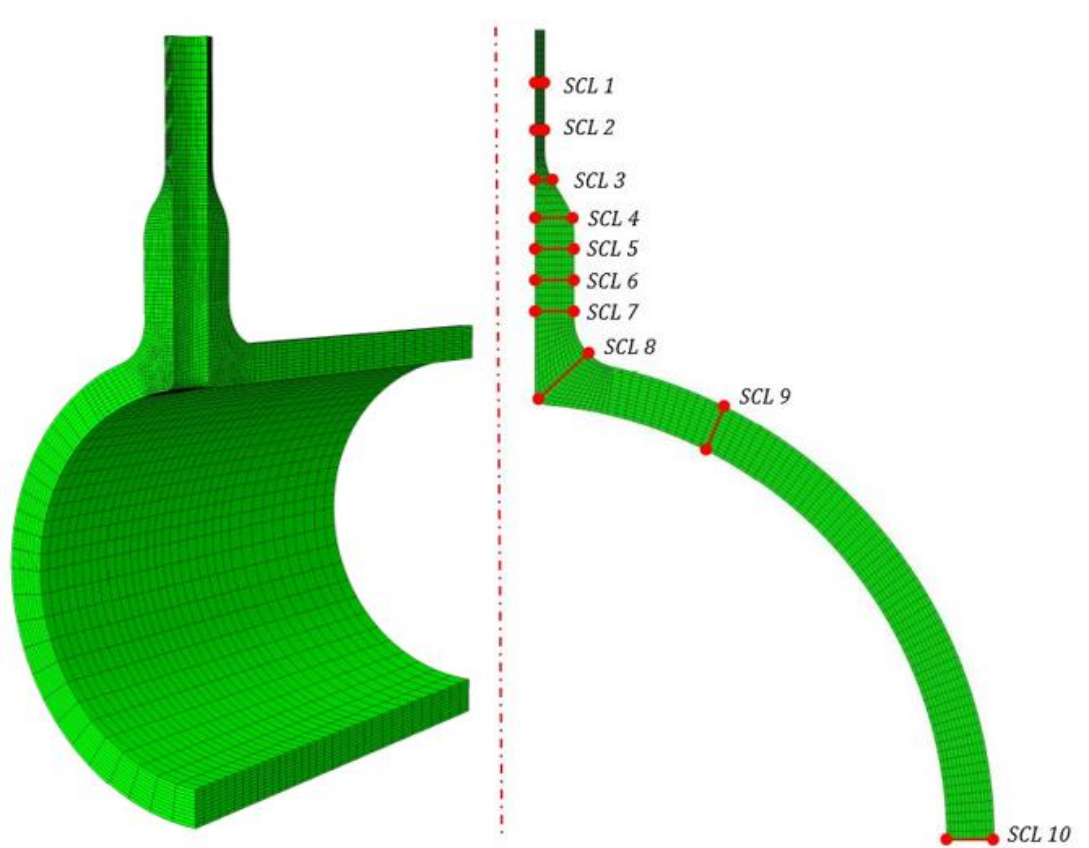

Figure 2. PWR MCL nozzle FE model.

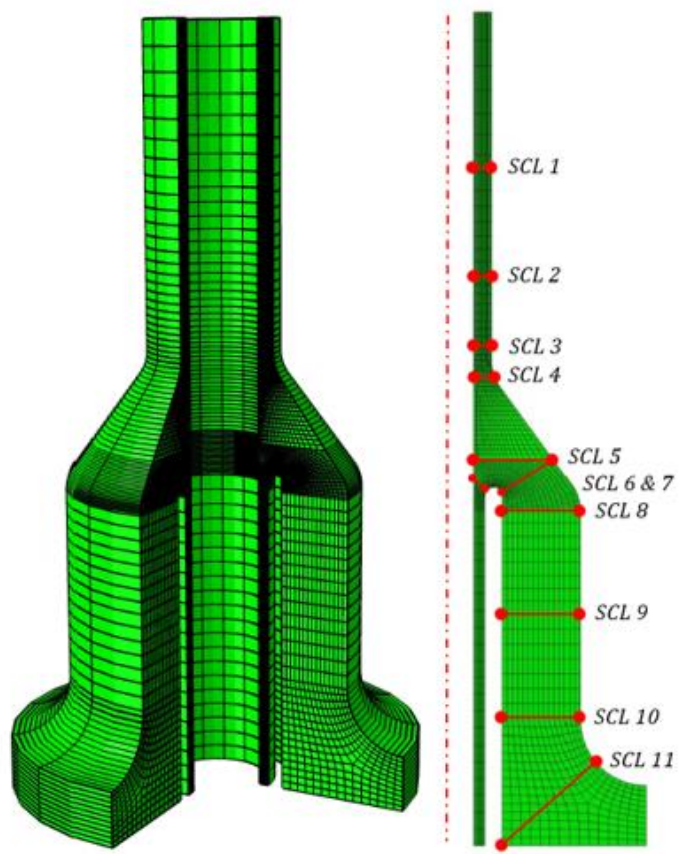

Figure 3. Nozzle thermal sleeve FE model.

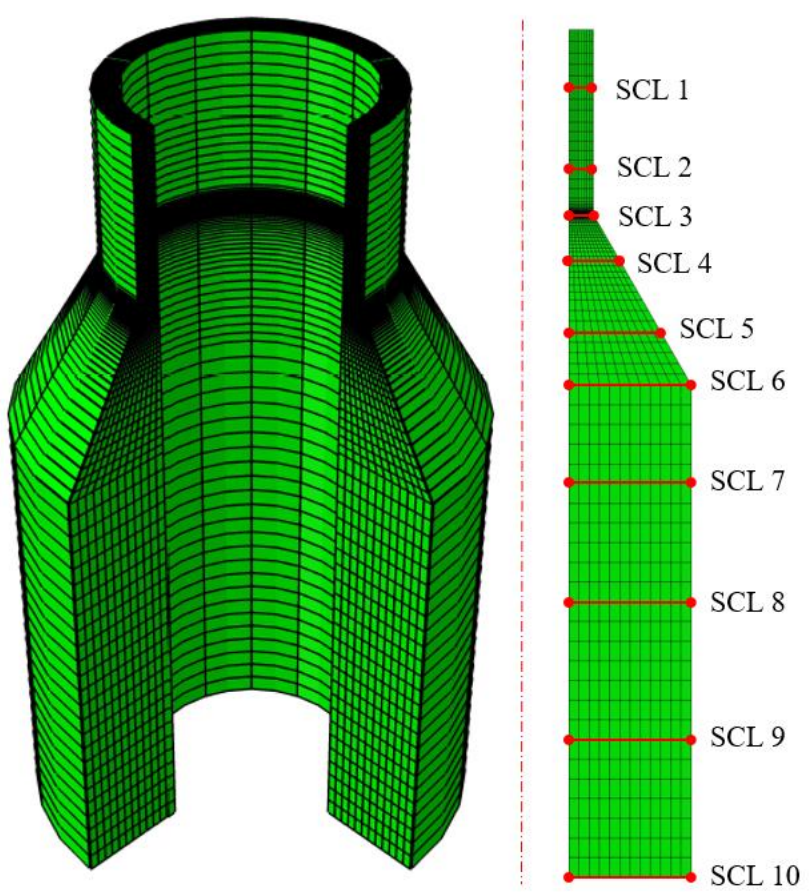

Figure 4. Tapered nozzle-in-vessel FE model.
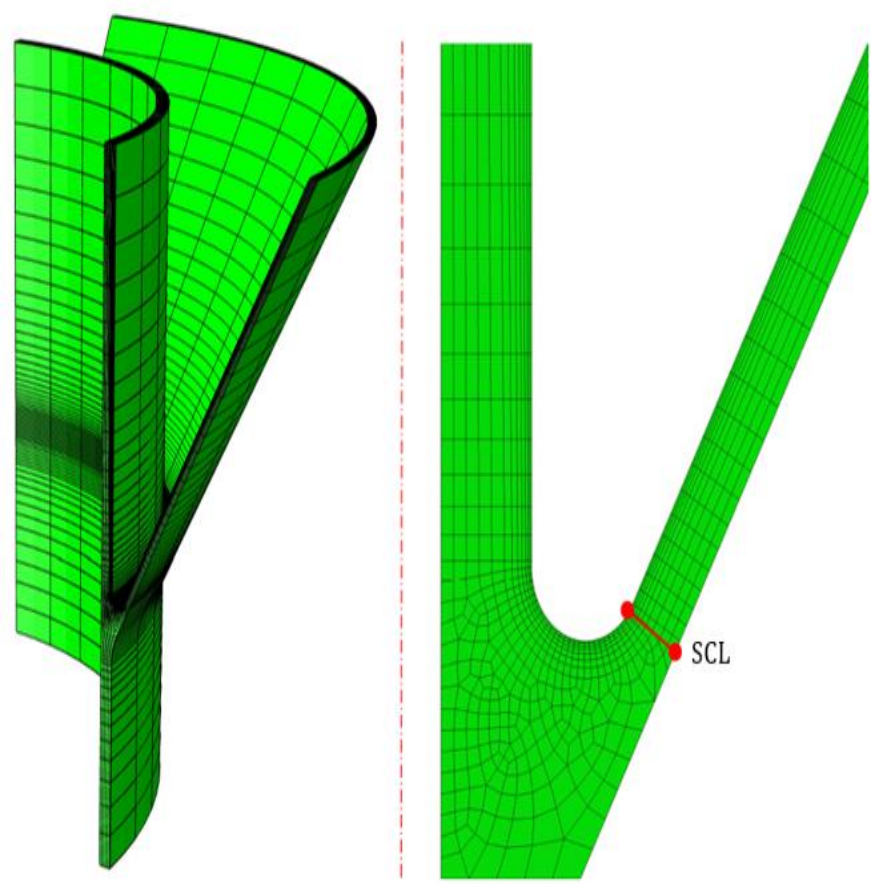

Figure 5. Y-piece FE model. 


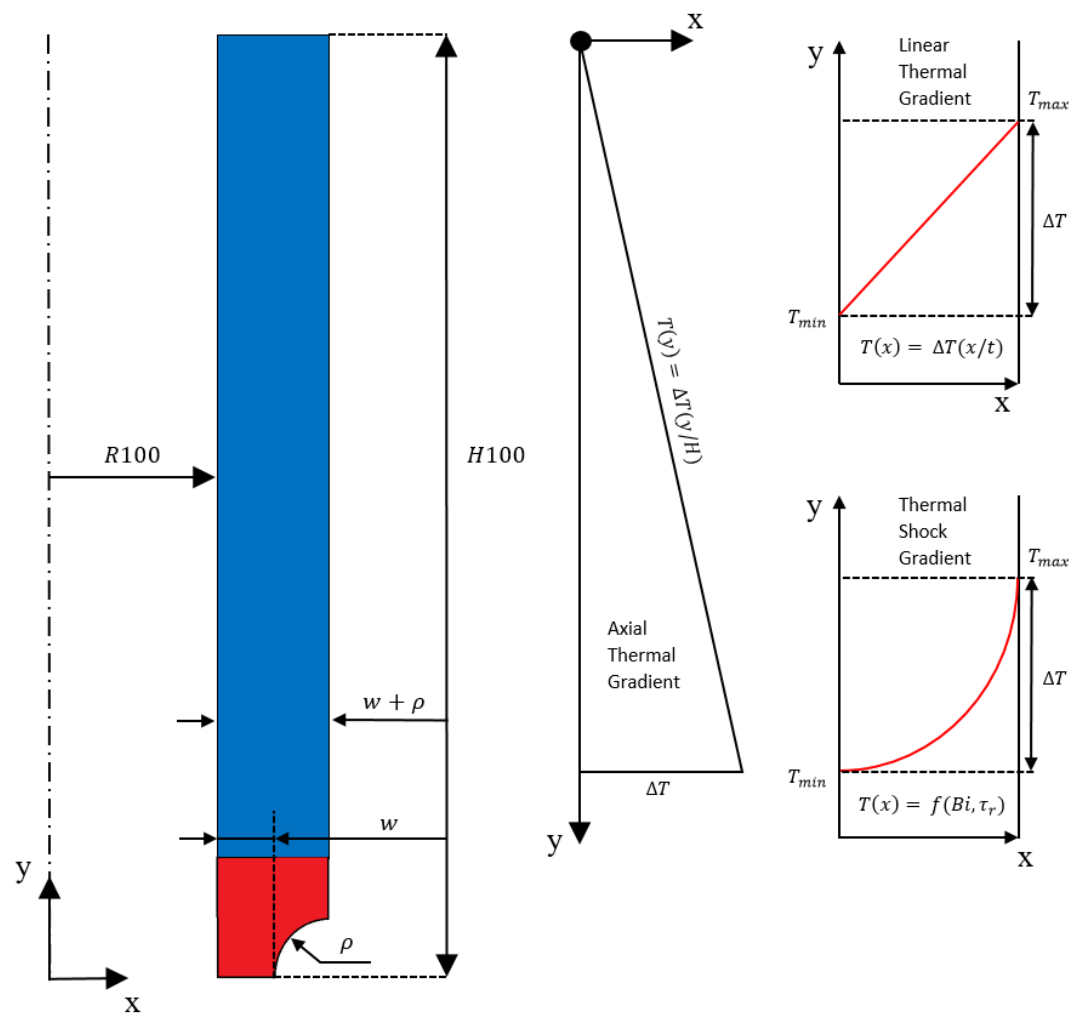

Figure 6. Description of parametric study conducted on notched cylinder FE models.

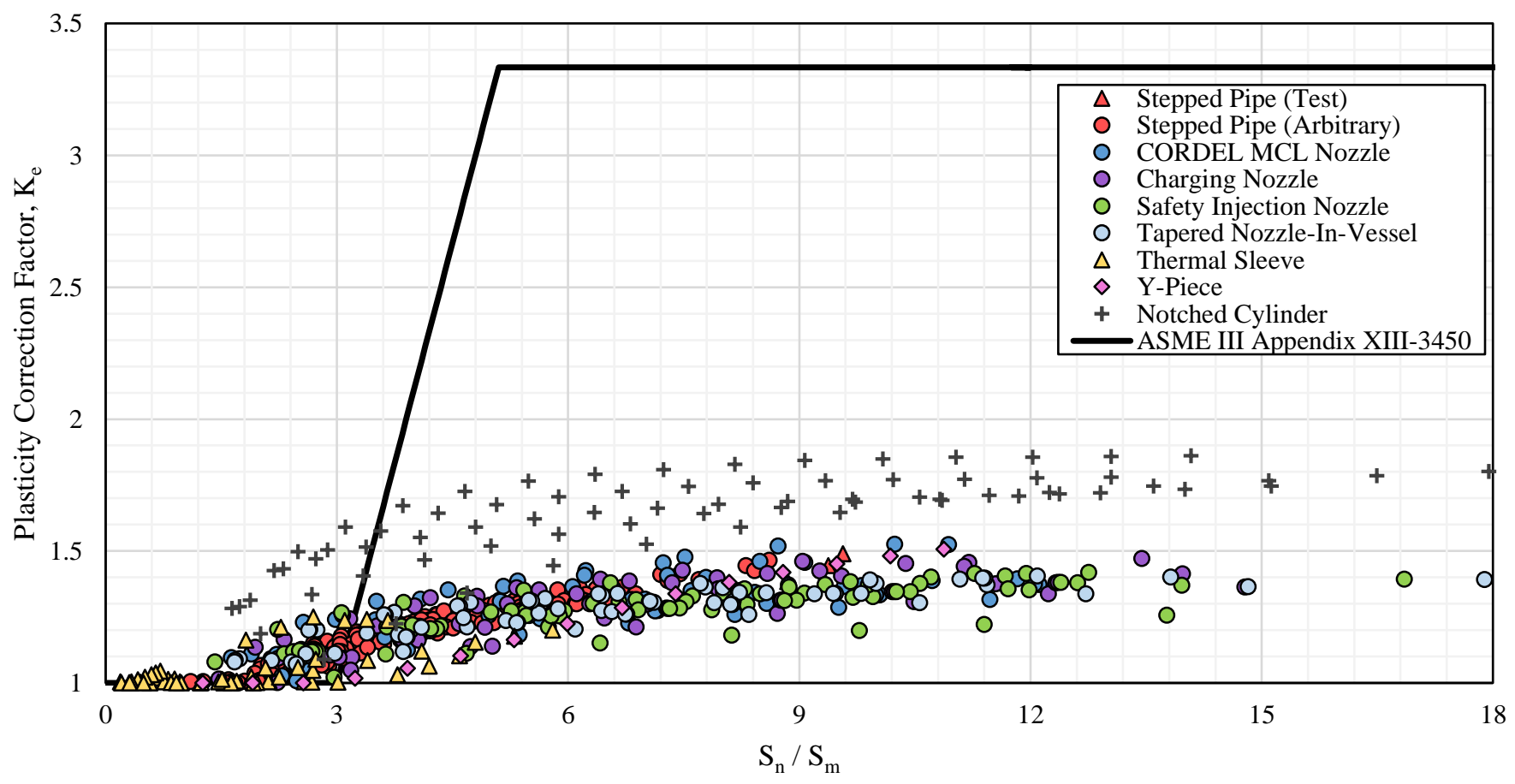

Figure 7. Summary of plasticity correction factors calculated from elastic-plastic FE models. 


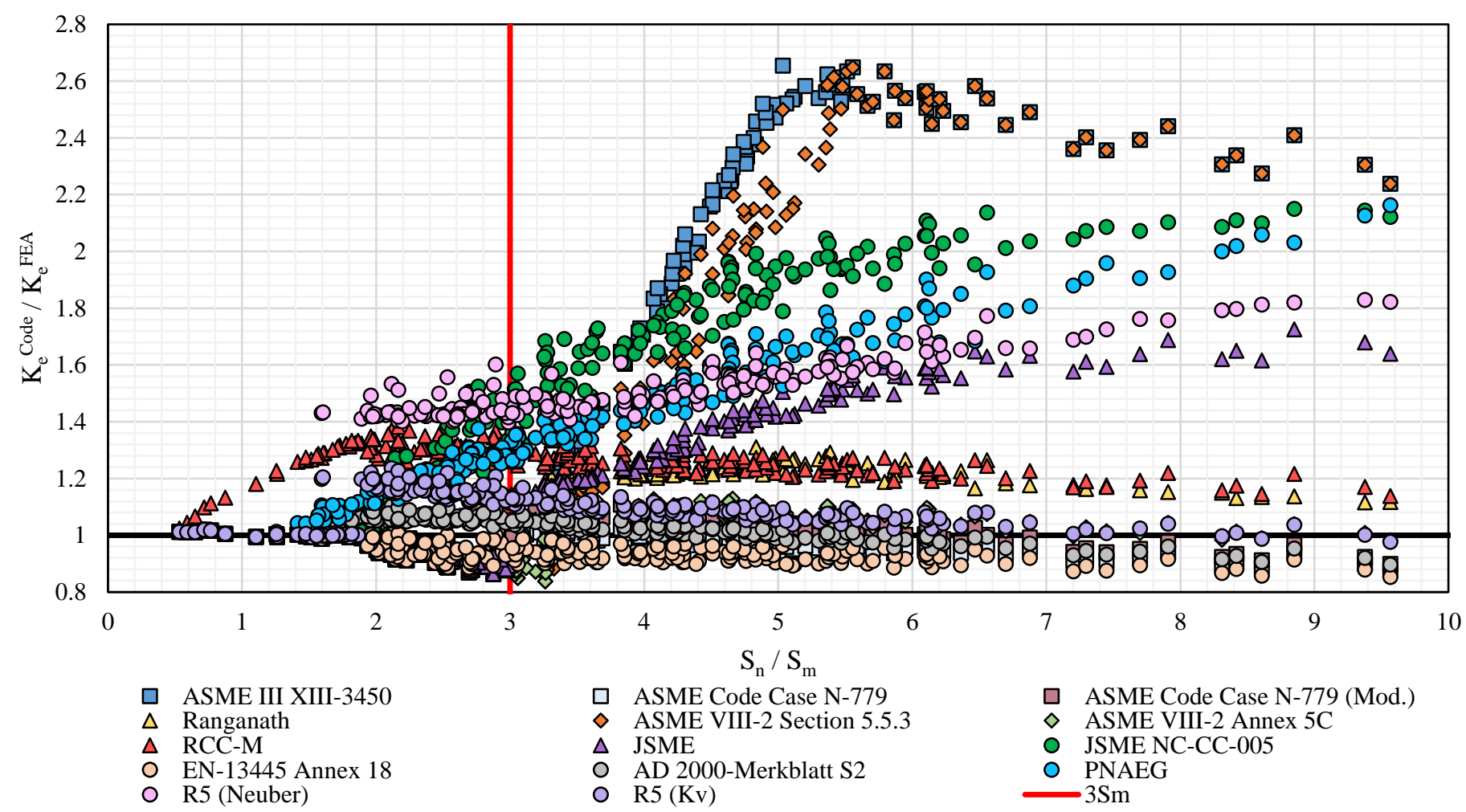

Figure 8. Relative performance of Code plasticity correction factors calculated for the stepped pipe FE model.

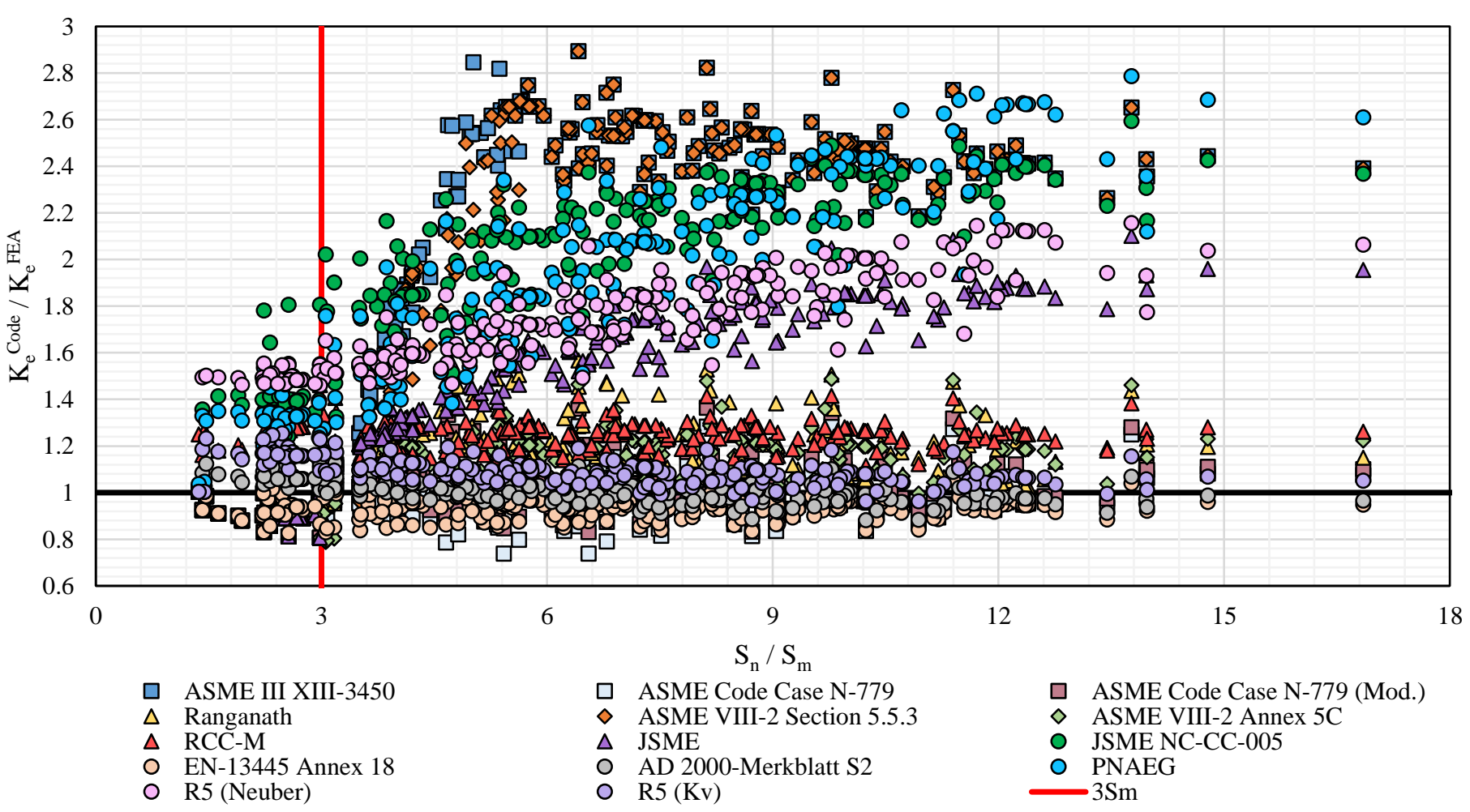

Figure 9. Relative performance of Code plasticity correction factors calculated for the PWR nozzle FE models. 


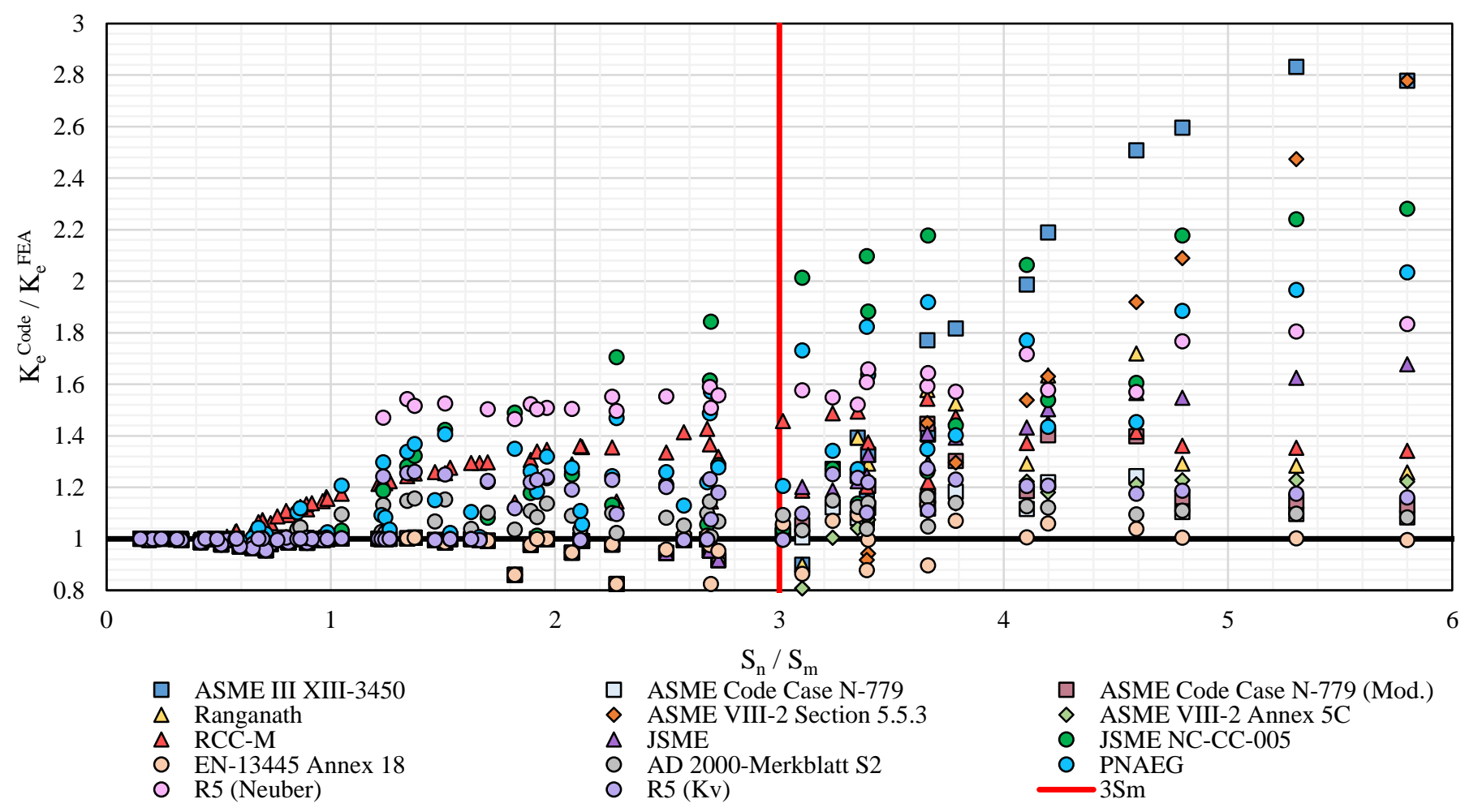

Figure 10. Relative performance of Code plasticity correction factors calculated for the thermal sleeve FE model.

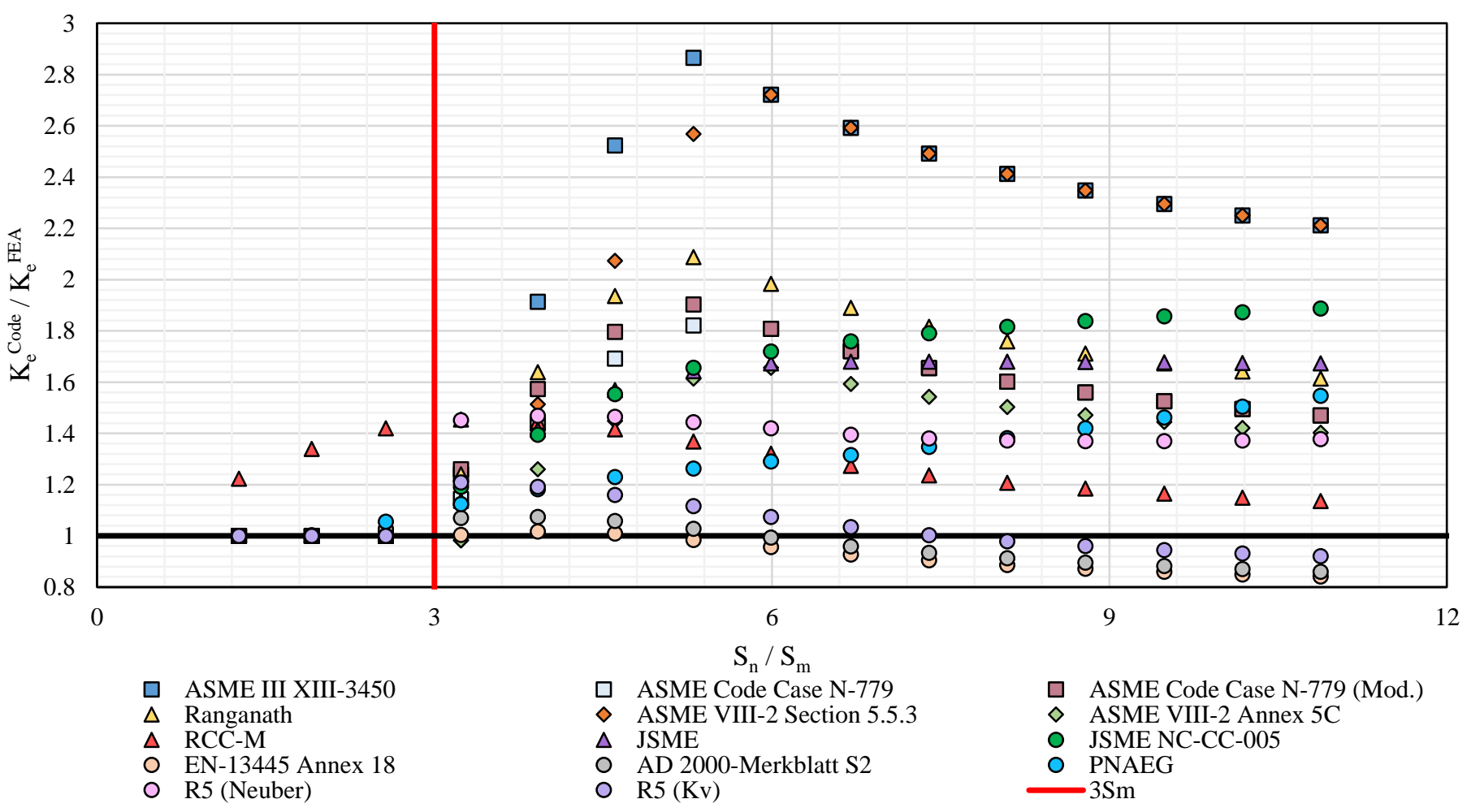

Figure 11. Relative performance of Code plasticity correction factors calculated for the Y-piece FE model. 


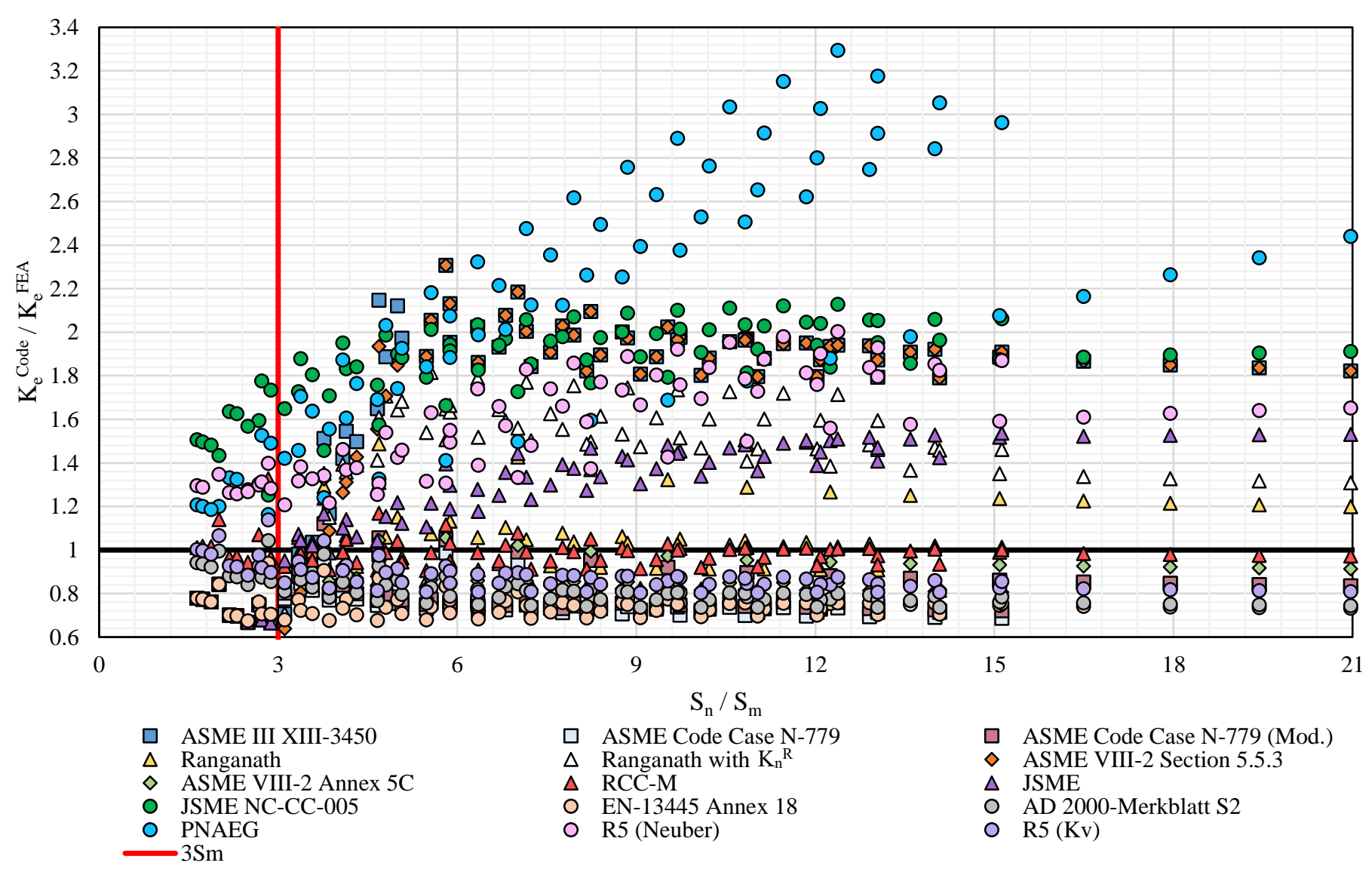

Figure 12. Relative performance of Code plasticity correction factors calculated for notched cylinder FE models.

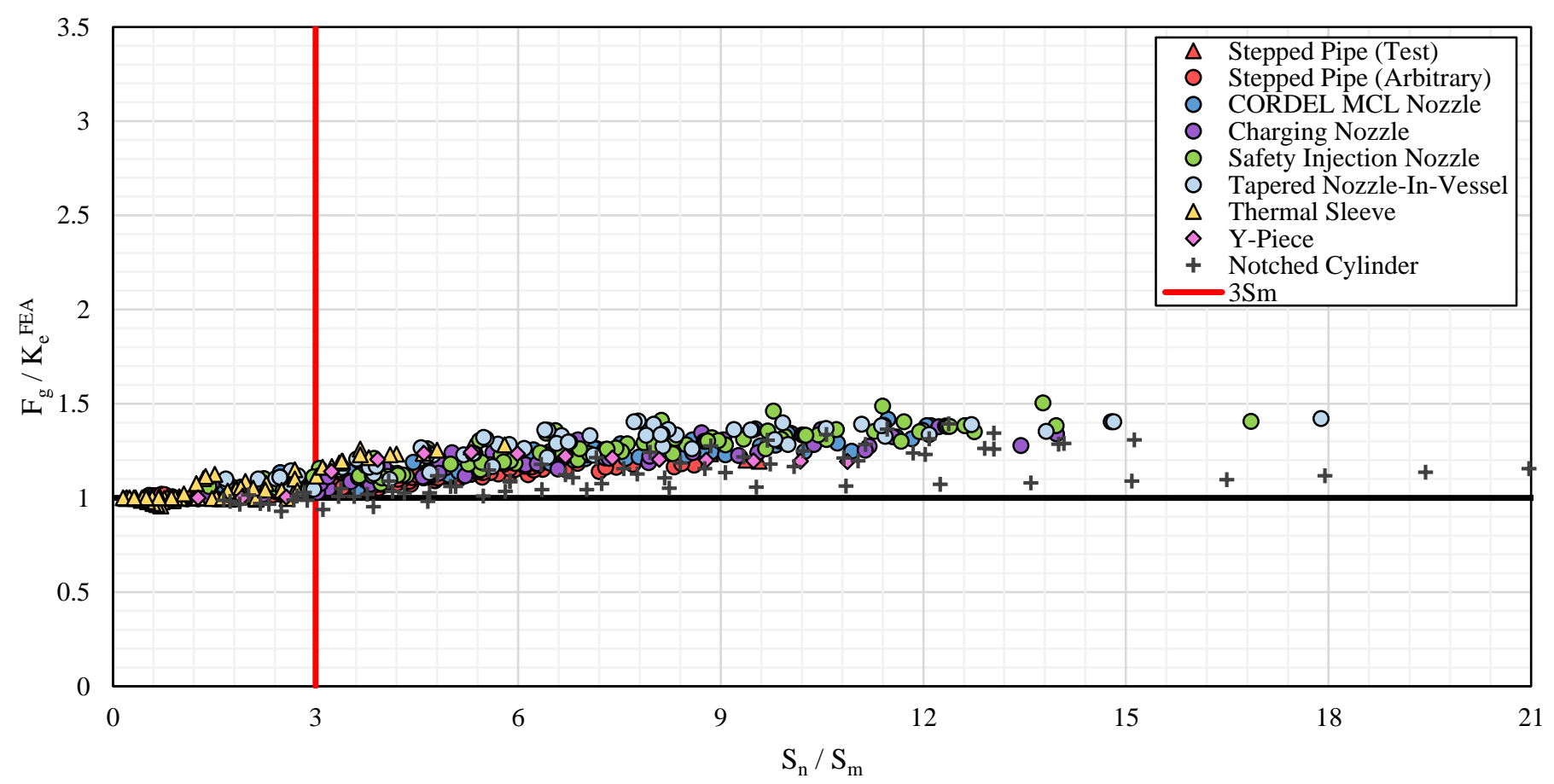

Figure 13. Relative performance of proposed correction factor, $F_{g}$, for all elastic-plastic FE models. 